\title{
Ammoniacal nitrogen removal by Eichhornia crassipes-based phytoremediation: process optimization using response surface methodology
}

\author{
W. H. T. Ting ${ }^{1} \cdot$ I. A. W. $\operatorname{Tan}^{1} \cdot$ S. F. Salleh ${ }^{1} \cdot$ N. Abdul Wahab ${ }^{1}$
}

Received: 27 November 2018 / Accepted: 18 February 2020 / Published online: 28 February 2020

(c) The Author(s) 2020

\begin{abstract}
Eutrophication is a serious environmental issue that needs urgent concern. There is necessity to treat wastewater with high ammoniacal nitrogen (AN) concentration to the permissible standard limit to protect the aquatic ecosystem. This study investigated the optimum condition for AN removal from wastewater using Eichhornia crassipes-based phytoremediation process. Face-centered central composite design (CCD) was employed as the experimental design, in which four operational variables including $\mathrm{pH}(4-10)$, retention time (2-14 days), macrophyte density $(5-30 \mathrm{~g} / \mathrm{L})$ and salinity $(0-5 \mathrm{~g} \mathrm{NaCl} / \mathrm{L})$ were involved in the study, while five responses were investigated, namely AN removal efficiency $\left(Y_{1}\right)$, fresh biomass growth $\left(Y_{2}\right)$, $\operatorname{COD}\left(Y_{3}\right)$, BOD $\left(Y_{4}\right)$ and TSS $\left(Y_{5}\right)$. AN removal was the main focus in this study. Through numerical optimization, the highest AN removal efficiency of $77.48 \%$ (initial AN concentration $=40 \mathrm{mg} / \mathrm{L}$ ) was obtained at the following optimum condition: $\mathrm{pH}$ 8.51 , retention time of 8.47 days, macrophyte density of $21.39 \mathrm{~g} / \mathrm{L}$ and salinity of $0 \mathrm{~g} \mathrm{NaCl} / \mathrm{L}$. The values predicted from the models agreed satisfactorily with the experimental values, which implied that response surface methodology was reliable and practical for experimental design developed using optimization of the phytoremediation process. The validation experiment using real semiconductor effluent further supported the high potential of the E. crassipes-based phytoremediation system to remove $\mathrm{AN}$ and other organic pollutants in this industrial effluent under optimal condition.
\end{abstract}

Keywords Wastewater treatment · Water hyacinth $\cdot$ Phytoremediation $\cdot$ Optimization · Ammoniacal nitrogen

\section{Introduction}

Semiconductor industry is recognized as one of the fastest growing industries due to the high global demand of electronic products (Huang et al. 2017). Semiconductor manufacturing processes are complex which include silicon growth, oxidation, doping, photolithography, etching, stripping, dicing, metallization, planarization, cleaning (Wong et al. 2013). During semiconductor manufacturing processes, a vast amount of water is consumed in chemical

Electronic supplementary material The online version of this article (https://doi.org/10.1007/s13201-020-1163-x) contains supplementary material, which is available to authorized users.

I. A. W. Tan

awitan@unimas.my

1 Department of Chemical Engineering and Energy Sustainability, Faculty of Engineering, Universiti Malaysia Sarawak, 94300 Kota Samarahan, Sarawak, Malaysia mechanical polishing (CMP) process for planarizing the surface of the silicon wafer, thus producing a huge quantity of wastewater containing both organic and inorganic pollutants (Nur Farehah et al. 2014). Ammoniacal nitrogen (AN) is one of the major pollutants present in semiconductor wastewater. High AN concentration in waterbodies will induce eutrophication, which subsequently contribute to oxygenlevel reduction and aquatic species loss (Xiang et al. 2015). In Malaysia, AN concentration in industrial effluent is necessary to be treated to comply with standard discharge limit of $20 \mathrm{mg} / \mathrm{L}$ as stipulated by the Environmental Quality Regulations 2009. However, existing AN removal technologies are found to be inefficient and inadequate, thus contributing to high AN content in semiconductor effluent ranging from 40 to $250 \mathrm{mg} \mathrm{AN} / \mathrm{L}$ (Aoudj et al. 2017). In order to overcome the aforementioned issue, there is an urge to look for an alternative solution which is accomplished with sustainable and cost-effective characteristics, especially in developing countries including Malaysia. 
Phytoremediation technology is defined as a natural treatment method which makes use of plants (phyto) to treat (remediate) various pollutants present in soil, sediment, surface water and groundwater environments (Fox et al. 2008). In recent years, phytoremediation gained keen interest among researchers to remove contaminants mainly due to its advantages including environmentally friendly and cost-effective (Paz-Alberto and Sigua 2013). The high efficiency of phytoremediation to remove a wide range of pollutants, which include heavy metals, radioactive materials, petroleum hydrocarbon, nutrients, organic contaminants and suspended substances, had been reported by many researchers (Rezania et al. 2015; Rai and Singh 2016; Mishra and Maiti 2017; Nayanathara and Bindu 2017). In order to operate a successful phytoremediation system, the selection of the suitable vegetative is crucial. Eichhornia crasssipes, commonly known as water hyacinth, is recommended as the AN phytoremediating candidate due to its characteristics such as fast growth rate, high nitrogen uptake capacity, easy to control and great adaptability to various wastewater environments (Ting et al. 2018). Besides, E. crasssipes also showed superior nitrogen removal efficiency compared to other macrophytes, such as Pistia stratiotes L. (Shah et al. 2014; Qin et al. 2016), Myriophyllum aquaticum Verdc (Shah et al. 2014), Ipomoea aquatica (Loan et al. 2014), Salvinia natans (Kumari and Tripathi 2013). Apart from the efficiency in AN removal, floating species such as E. crasssipes is more convenient and less expensive to be harvested compared to small plants (e.g., phytoplankton) or submerged plants (Valipour et al. 2015).

Other than vegetative selection, phytoremediation efficiency is also significantly influenced by the environmental factors, such as $\mathrm{pH}$, temperature, salinity, climate, moisture and types of contaminants present in remediating medium (Lu et al. 2008, 2013; Zhang et al. 2010; Pedron and Petruzzelli 2011). In order to determine the highest treatment efficiency together with the reduced operation cost, optimization process is necessary. Response surface methodology (RSM) is a group of mathematical and statistical techniques which is helpful for modeling and problem analysis. Since RSM can be employed for process parameters modeling and optimization, it is widely applied in wastewater treatment process in order to achieve the desired goals especially for enhancement of pollutants removal efficiency and reduction of operating cost (Bashir et al. 2015). Numerous literatures have reported on the phytoremediation performance optimization using RSM, such as diesel-contaminated water (AlBaldawi et al. 2014), heavy metal-contaminated soil or solution (Caraiman et al. 2012; Kumar et al. 2018; Titah et al. 2018), palm oil mill secondary effluent (POMSE) (Darajeh et al. 2016), petrochemical wastewater (Samimi and Moghadam 2018), tofu wastewater (Seroja et al. 2018) and polluted stormwater (Yahyapour et al. 2014). Even though phytoremediation technology is widely applied in treating various types of wastewater, the study on phytoremediation of AN wastewater is rarely found. To the best of our knowledge, the application of RSM on AN phytoremediation process using E. crasssipes has not been reported. Thus, the objective of this study is to perform RSM optimization to acquire the optimal condition which aims to enhance the AN removal efficiency through $E$. crasssipes-based phytoremediation process. The optimization study would be beneficial for the design of phytoremediation process to remove $\mathrm{AN}$ effectively from the industrial effluent.

\section{Materials and methods}

\section{Industrial effluent collection and characterization}

The semiconductor effluent used in this study was obtained from a semiconductor factory located at Samajaya Free Industrial Zone, Sarawak, Malaysia. The effluent sample was collected from the final discharge point of the wastewater treatment plant, preserved at $4{ }^{\circ} \mathrm{C}$, and was analyzed within a day in order to minimize the experimental error due to degradation of the sample. The parameters analyzed were $\mathrm{pH}$, temperature, turbidity, $\mathrm{BOD}_{5}, \mathrm{COD}$, TSS, heavy metals $(\mathrm{Cd}, \mathrm{Cu}, \mathrm{F}, \mathrm{Fe}, \mathrm{Pb}, \mathrm{Zn}$ ) and $\mathrm{AN}$. Effluent characterization was performed to determine the experimental matrix to be used in the process optimization design. The characteristics of the semiconductor effluent are shown in Table 1.

\section{Phytoremediation setup and operation}

Laboratory scale phytoremediation tanks were constructed with a dimension of $0.45 \mathrm{~m}$ length $\times 0.30 \mathrm{~m}$ width $\times 0.30 \mathrm{~m}$ height by using acrylic glass. The water capacity was

Table 1 Semiconductor effluent characteristics

\begin{tabular}{lll}
\hline Parameters & Units & Values \\
\hline $\mathrm{pH}$ & - & 6.54 \\
Temperature & ${ }^{\circ} \mathrm{C}$ & 26.5 \\
BOD $_{5}$ & $\mathrm{mg} / \mathrm{L}$ & 30 \\
COD & $\mathrm{mg} / \mathrm{L}$ & 145 \\
TSS & $\mathrm{mg} / \mathrm{L}$ & 6 \\
AN & $\mathrm{mg} / \mathrm{L}$ & 36.40 \\
Turbidity & $\mathrm{NTU}$ & 1.9275 \\
Heavy metals & & \\
Cadmium $(\mathrm{Cd})$ & $\mathrm{mg} / \mathrm{L}$ & 0.0074 \\
Copper $(\mathrm{Cu})$ & $\mathrm{mg} / \mathrm{L}$ & 0.0131 \\
Fluoride $(\mathrm{F})$ & $\mathrm{mg} / \mathrm{L}$ & 0.4090 \\
Lead $(\mathrm{Pb})$ & $\mathrm{mg} / \mathrm{L}$ & 0.2244 \\
Iron $(\mathrm{Fe})$ & $\mathrm{mg} / \mathrm{L}$ & 0.0000 \\
Zinc $(\mathrm{Zn})$ & $\mathrm{mg} / \mathrm{L}$ & 0.0000 \\
\hline
\end{tabular}

مدينة الملك عبدالعزيز

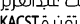
Springer 
$20.25 \mathrm{~L}$ with an effective depth of $15 \mathrm{~cm}$. Native Eichhornia crassipes was collected and washed gently prior to the experimental use. Phytoremediation process was carried out in batch mode condition, in which each treatment system contained E. crassipes and these tanks were placed under the outdoor condition and arranged in such a way that light availability was maximum. Synthetic wastewater with AN concentration of $40 \mathrm{mg} / \mathrm{L}$ was prepared using ammonium chloride $\left(\mathrm{NH}_{4} \mathrm{Cl}\right)$. $\mathrm{pH}$ adjustment was performed using $3 \mathrm{M}$ hydrochloric acid $(\mathrm{HCl})$ and $3 \mathrm{M}$ sodium hydroxide $(\mathrm{NaOH})$ solution. Tap water was added to the tank regularly to maintain constant water volume. Rainfall effect was prevented by shedding the experimental area with transparent polyethylene sheet. Fresh biomass weight of $E$. crassipes was measured before and after each phytoremediation process.

\section{Wastewater analysis}

For each wastewater sample, $\mathrm{pH}$ was measured on site using pH meter (Model pH 5+, Eutech Instruments). After each phytoremediation process, $500 \mathrm{~mL}$ of wastewater sample was collected and preserved at $4{ }^{\circ} \mathrm{C}$ before analysis to minimize experimental error due to sample degradation. The analysis of physiochemical parameters of the wastewater samples involved in AN, chemical oxygen demand (COD), 5-day biochemical oxygen demand $\left(\mathrm{BOD}_{5}\right)$ and total suspended solids (TSS). AN content in the wastewater sample was analyzed after each phytoremediation process according to salicylate method (Program 343N) using a multiparameter portable colorimeter (Model DR900, Hach). COD, BOD 5 and TSS analysis were conducted according to Standard Methods for Examination of Water and Wastewater (APHA 2005). For COD analysis, water sample solution was placed for digestion under $150{ }^{\circ} \mathrm{C}$ for $2 \mathrm{~h}$ in COD reactor block (Model DRB 200, Hach, USA) prior to titration using 0.1 M ferrous ammonium sulfate (FAS) solution. For $\mathrm{BOD}_{5}$ analysis, water sample was incubated at $20{ }^{\circ} \mathrm{C}$ for 5 days with measurement of both initial and final dissolved oxygen (DO) level. For TSS analysis, filtration method was applied by using glass microfiber disks $47 \mathrm{~mm}$, followed by drying process in oven at $103-105^{\circ} \mathrm{C}$ for $1 \mathrm{~h}$.

\section{RSM optimization design}

RSM optimization study was performed using Design Expert software version 7.1.6 (STAT-EASE Inc., Minneapolis, USA). Face-centered central composite design (CCD) was employed as the design of experiment (DoE), in which the design consisted of 30 runs, with 6 center points and 24 axial points, and $\alpha=1$. Four variables including $\mathrm{pH}$ $(A)$, retention time $(B)$, macrophyte density $(C)$ and salinity $(D)$ were chosen as the independent variables. Preliminary studies were conducted to select the value range for each input variable to be employed for optimization study, as shown in Table 2. Five responses (dependent variables) were investigated, namely AN removal efficiency $\left(Y_{1}\right)$, fresh biomass growth $\left(Y_{2}\right), \operatorname{COD}\left(Y_{3}\right), \operatorname{BOD}\left(Y_{4}\right)$ and TSS $\left(Y_{5}\right)$. AN removal efficiency was the main focus in this study, whereas fresh biomass growth of the plants was another significant response to be considered since there was close and positive correlation between plants' growth and phytoremediation performance. Other physiochemical parameters (i.e., $\mathrm{COD}, \mathrm{BOD}_{5}$ and TSS) were considered as the monitoring responses to investigate the potential risk of extra pollutant load in the treated wastewater posed by $E$. crassipes-based phytoremediation system. All experiments were carried out in triplicate, and the mean values were reported. Models describing the relationship between each dependent variable and the independent variables were developed, and the fitness of the models developed was evaluated through analysis of variance (ANOVA) and diagnostics plots. Numerical optimization was performed to obtain the optimum conditions for achieving AN removal efficiency higher than 50\% to meet the standard discharge limit of $20 \mathrm{mg} / \mathrm{L}$ with the lowest retention time and pollution load which included COD, BOD and TSS. To verify the optimization results, experiments of five replicates which simulated the predicted optimum conditions were conducted to compare the actual results with the predicted optimal values. Another set of validation experiment with three replicates was also conducted using real semiconductor wastewater to evaluate the efficiency of pollutant removal using E. crassipes-based phytoremediation system under optimal condition.

\section{Results and discussion}

\section{Model fitting, regression analysis and diagnostics}

As suggested by the software, five models in terms of coded factors describing the relationship between each dependent variable and the independent variables were obtained. Coded Eq. was useful for identifying the relative impact of the factors by comparing the factor coefficients. For response AN removal efficiency $\left(Y_{1}\right)$, the two-factor interaction (2FI) model was selected, as shown in Eq. 1. Equations 2 and

Table 2 Independent variables and levels considered for the design of experiment (DoE)

\begin{tabular}{|c|c|c|c|}
\hline Independent variables & Units & - 1 Level & + 1 Level \\
\hline $\mathrm{pH}(A)$ & - & 4 & 10 \\
\hline Retention time $(B)$ & days & 2 & 14 \\
\hline Macrophyte density $(C)$ & $\mathrm{g} / \mathrm{L}$ & 5 & 30 \\
\hline Salinity $(D)$ & $\mathrm{g} \mathrm{NaCl} / \mathrm{L}$ & 0 & 5 \\
\hline
\end{tabular}


3 on the other hand showed the selected quadratic models for responses of fresh biomass growth $\left(Y_{2}\right)$ and $\operatorname{COD}\left(Y_{3}\right)$, respectively. For responses of $\operatorname{BOD}\left(Y_{4}\right)$ and $\operatorname{TSS}\left(Y_{5}\right)$, the linear models were selected, as described in Eqs. 4 and 5, respectively. The positive coefficient values indicated synergistic effect, while the negative coefficient values indicated antagonistic effect.

$$
\begin{aligned}
Y_{1}= & 58.28+28.22 A+15.62 B+4.75 C-5.79 D \\
& +0.44 A B-8.15 A C+4.50 A D+5.03 B C \\
& -4.09 B D+1.38 C D \\
Y_{2}= & 170.32-19.67 A+42.24 B+13.36 C-61.98 D \\
& -5.56 A B-1.31 A C-16.15 A D+24.06 B C \\
& -26.85 B D-30.60 C D-73.01 A^{2}-28.51 B^{2} \\
& -37.43 C^{2}-8.51 D^{2} \\
Y_{3}= & 19.18+26.44 A+12.22 B+14.17 C+15.06 D \\
& +17.69 A B+6.06 A C+6.44 A D+10.81 B C \\
& +0.19 B D-6.19 C D+25.77 A^{2}+4.77 B^{2} \\
& +2.27 C^{2}+15.27 D^{2} \\
Y_{4}= & 3.04+0.14 A+1.73 B+0.50 C+0.76 D \\
Y_{5}= & 6.15+0.14 A+0.34 B+0.18 C+0.50 D
\end{aligned}
$$

The fitness of the models developed was evaluated through both regression analysis and diagnostics plots. The model adequacy was justified through ANOVA. The
ANOVA of the model of response AN removal efficiency $\left(Y_{1}\right)$ is shown in Table 3 . The model $F$ value of 19.77 implied that the model was significant. There was only $0.01 \%$ chance that an $F$ value this large could occur due to noise. $p$ values less than 0.0500 indicated that the model terms were significant. In this case, $A, B, D, A C$ were significant model terms. In other words, factors $\mathrm{pH}(A)$, retention time $(B)$ and salinity $(D)$ played significant roles in affecting the AN removal efficiency. Values greater than 0.1000 indicated that the model terms were not significant. The lack of fit $F$ value of 1.37 implied that the lack of fit was not significantly relative to the pure error. There was $44.78 \%$ chance that a lack of fit $F$ value this large could occur due to noise (Al-Baldawi et al. 2014). According to fit statistics, the determination coefficient $\left(R^{2}\right)$ obtained was 0.9208 , which indicated that the model explained $92.08 \%$ of the response variability. The $R^{2}$ value also reflected a good fit of the model. The adjusted $R^{2}$ was 0.8742 , which was considered moderately high to confirm the model significance. Adequate precision was the measurement of signal-to-noise ratio, and a ratio greater than 4 was desirable. The adequate precision was found to be 15.7214, which indicated an adequate signal and implied that the model could be used to navigate the design space (Al-Baldawi et al. 2014; Kumar et al. 2018).

The diagnostics of the model statistical properties are presented in Fig. 1, which included normal probability plot, predicted versus actual plot, leverage plot and externally studentized residuals plot. The normality assumption was satisfied since the residual plot approximated along a straight line, as shown in Fig. 1a. Figure 1b shows the predicted versus actual plot. The actual values were obtained from
Table 3 Analysis of variance (ANOVA) for response surface 2FI model for AN removal efficiency $\left(Y_{1}\right)$

\begin{tabular}{lrrlrr}
\hline Source & Sum of squares & $\begin{array}{l}\text { Degree of free- } \\
\text { dom }(d f)\end{array}$ & Mean square & $F$ value & $p$ value \\
\hline Model & $21,828.75$ & 10 & 2182.88 & 19.77 & $<0.0001$ \\
$A$ & $14,333.50$ & 1 & $14,333.50$ & 129.80 & $<0.0001$ \\
$B$ & 4394.22 & 1 & 4394.22 & 39.79 & $<0.0001$ \\
$C$ & 405.37 & 1 & 405.37 & 3.67 & 0.0723 \\
$D$ & 602.74 & 1 & 602.74 & 5.46 & 0.0320 \\
$A B$ & 3.13 & 1 & 3.13 & 0.0284 & 0.8682 \\
$A C$ & 1063.09 & 1 & 1063.09 & 9.63 & 0.0065 \\
$A D$ & 324.54 & 1 & 324.54 & 2.94 & 0.1046 \\
$B C$ & 404.21 & 1 & 404.21 & 3.66 & 0.0727 \\
$B D$ & 267.49 & 1 & 267.49 & 2.42 & 0.1380 \\
$C D$ & 30.47 & 1 & 30.47 & 0.2759 & 0.6062 \\
Residual & 1877.21 & 17 & 110.42 & & \\
Lack of fit & 1623.95 & 14 & 116.00 & 1.37 & 0.4478 \\
Pure error & 253.26 & 3 & 84.42 & & \\
SD & 10.51 & & $R^{2}$ & 0.9208 & \\
Mean & 58.28 & & Adjusted $R^{2}$ & 0.8742 & \\
C.V. $\%$ & 18.03 & & Adequate precision & 15.7214 & \\
\hline
\end{tabular}

مدينة الملك عبدالعزيز KACST 

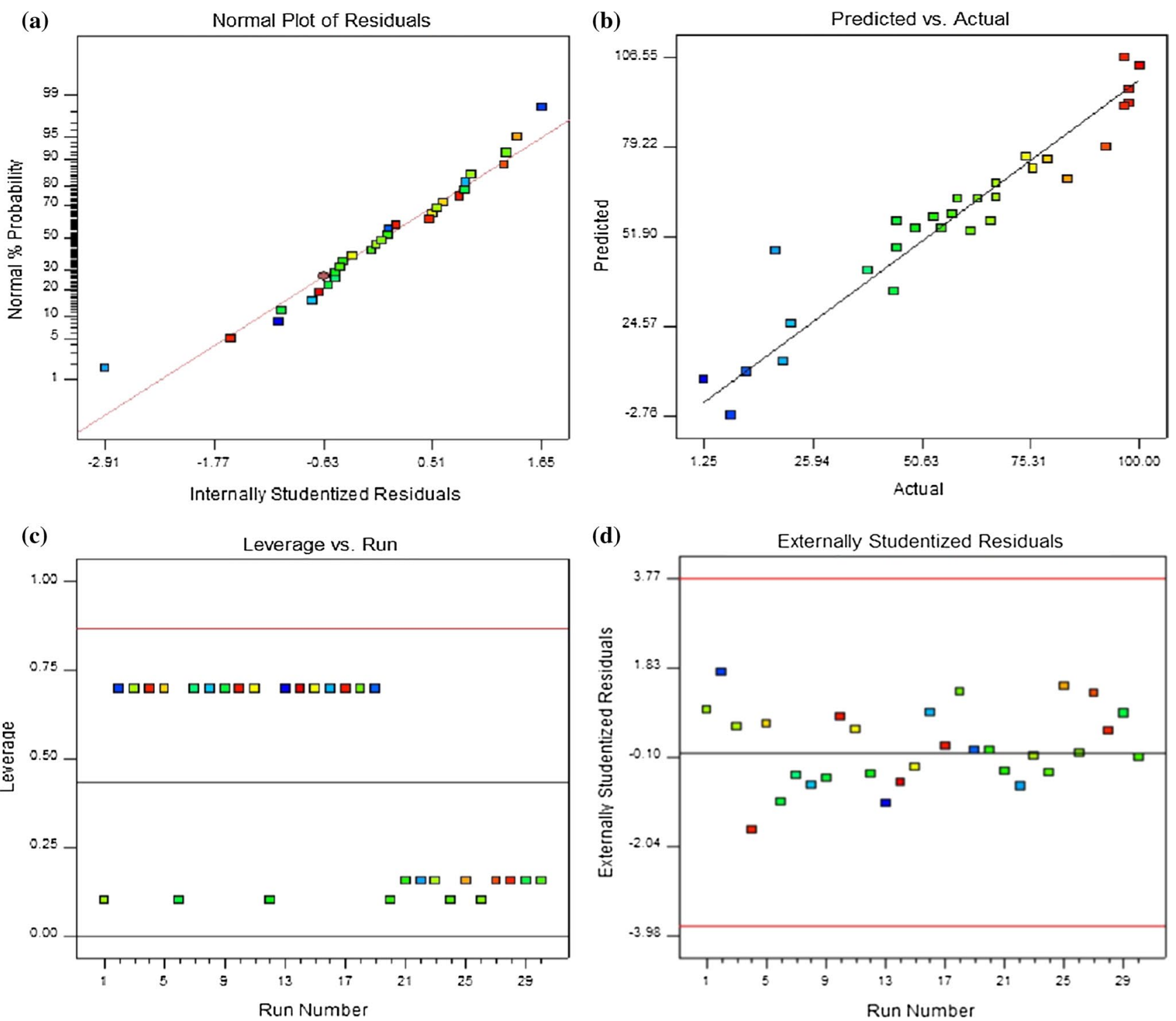

Fig. 1 Diagnostics of the model statistical properties for AN removal efficiency $\left(Y_{1}\right)$

the experiments, while the predicted values were obtained from the model fitting method. As shown in Fig., the predicted values fitted quite well with the actual values. The leverage plot is shown in Fig. 1c. The results portrayed that the leverage value was within $0-1$ and no point fell above the threshold (twice the average leverage) for this statistic. Figure 1d shows the externally studentized residuals plot for outlier determination. All the results were within the range of externally studentized residuals, which indicated that there was no outlier detected.

According to the ANOVA of response fresh biomass growth $\left(Y_{2}\right)$, the quadratic model $F$ value of 7.39 implied that the model was significant. There was only $0.04 \%$ chance that an $F$ value this large could occur due to noise. In this case, $B, D, B D, C D, A^{2}$ were significant model terms. The
$R^{2}$ obtained for Eq. 2 was 0.8884 , which indicated that the model explained $88.84 \%$ of the response variability. The $R^{2}$ value also reflected a moderate fit of the model. The adjusted $R^{2}$ was 0.7682 , which was considered moderately high to confirm the model significance. For the responses of COD $\left(Y_{3}\right)$, BOD $\left(Y_{4}\right)$ and TSS $\left(Y_{5}\right)$, the $R^{2}$ obtained was 0.8252 , 0.3824 and 0.0323 , respectively. Even though the $R^{2}$ value of response $\operatorname{COD}\left(Y_{3}\right)$ reflected a moderate fit of the model, the low $R^{2}$ values obtained for responses BOD $\left(Y_{4}\right)$ and TSS $\left(Y_{5}\right)$ implied that the models were insignificant. This indicated that the input variables were poorly correlated with the output responses BOD $\left(Y_{4}\right)$ and TSS $\left(Y_{5}\right)$. Besides, this was probably due to the differed dirt condition of $E$. crassipes upon collection which contributed to the randomized increment values of contaminants in treated wastewater. 

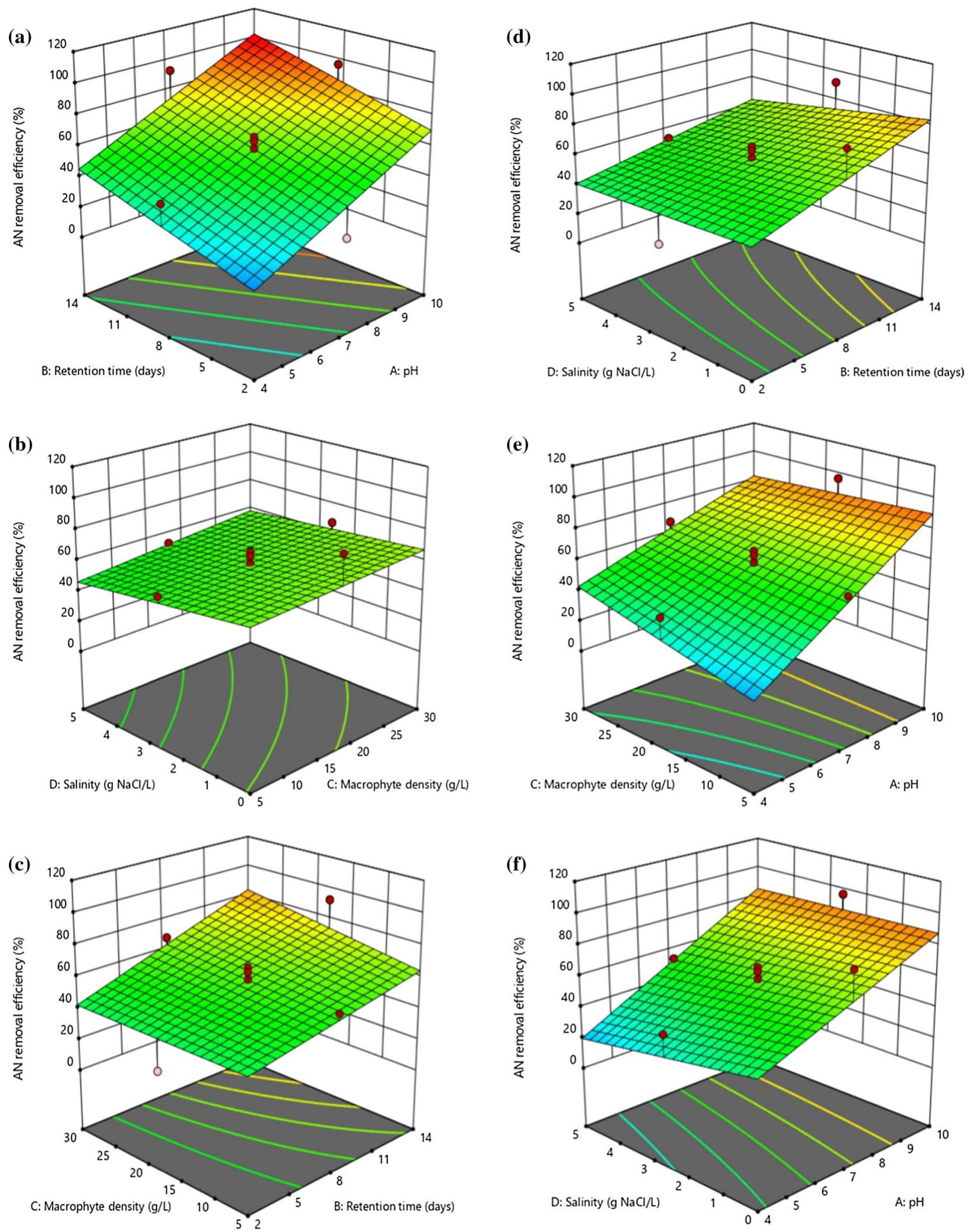

AN removal efficiency (\%)

Design Points 
4Fig. 2 Interactive effect of multivariable $\left(X_{1} X_{2}\right)$ on AN removal efficiency $\left(Y_{1}\right)$ : a pH and retention time; $\mathbf{b}$ macrophyte density and salinity; $\mathbf{c}$ retention time and macrophyte density; $\mathbf{d}$ retention time and salinity; e pH and macrophyte density; $\mathbf{f} \mathrm{pH}$ and salinity

\section{Interactive effects between variables}

\section{Interactive effect of $\mathrm{pH}(A)$ and retention time $(B)$}

Figure $2 \mathrm{a}$ shows the interactive effect of $\mathrm{pH}(A)$ and retention time $(B)$ on AN removal efficiency at actual factor conditions, at which macrophyte density was fixed at $17.5 \mathrm{~g} / \mathrm{L}$ and salinity was fixed at $2.5 \mathrm{~g} / \mathrm{L}$. Suitable $\mathrm{pH}$ range of treatment medium is crucial to provide healthy vegetative growth for ensuring an effective phytoremediation process, at which the pH range for optimal growth of E. crassipes was reported as 5.8-7.5 by Edaigbini et al. (2015) and 6-8 by Rezania et al. (2015). It is demonstrated in Fig. 2a that the increase in both $\mathrm{pH}$ value and retention time led to the increase in AN removal efficiency. At higher $\mathrm{pH}$ value, high $\mathrm{AN}$ removal $(>80 \%)$ was obtained with shorter retention time. This was because at higher $\mathrm{pH}$ condition, ammonia volatilization occurred at a faster rate (El-Gendy et al. 2004). The findings agreed with the study conducted by El-Gendy et al. (2004) which reported the increase in AN removal via volatilization at higher $\mathrm{pH}$ and it became more significant at $\mathrm{pH}>8$. Under low $\mathrm{pH}$ condition $(\mathrm{pH}=4)$, the AN removal efficiency was relatively low for all levels of retention time. Low $\mathrm{pH}$ condition acted as inhibitor for healthy plant growth, and intolerance symptoms such as yellowing and withering of E. crassipes were observed during the experiment (Caicedo et al. 2000; Gupta et al. 2012).

\section{Interactive effect of macrophyte density $(C)$ and salinity $(E)$}

Figure $2 \mathrm{~b}$ shows the interactive effect of macrophyte density $(C)$ and salinity $(D)$ on AN removal efficiency. Under fixed conditions of $\mathrm{pH} 7$ and retention time of 8 days, the response surface plot showed that the achievable AN removal efficiency was lower than $70 \%$. It also indicated that AN removal efficiency tended to improve when higher macrophyte density and lower salinity were applied. A higher macrophyte density would form a tight root-biofilm network to maximize the contact between wastewater medium and root zone for microbial activity to degrade and assimilate pollutants, which served as filtration and entrapment media, and minimized the light penetration into water medium to inhibit algal growth (Nahlik and Mitsch 2006; Dixit et al. 2011; Mishra and Maiti 2017; Nayanathara and Bindu 2017). Salinity is another significant factor that affects phytoremediation efficiency, at which Neffati and Marzouk (2010) and Zhao et al. (2014) revealed that increasing salinity adversely affected plants' growth and AN removal efficiency, which was probably due to reduced chlorophyll content caused by low osmotic potential of the medium. It was also found that the higher AN removal efficiency could be obtained at high salinity condition only when higher macrophyte density was employed. High macrophyte density could provide less stressful growth environment caused by the high salinity, consequently enhancing the AN removal performance (Zhao et al. 2014).

\section{Interactive effect of retention time $(B)$ and macrophyte density $(C)$}

The interactive effect of retention time $(B)$ and macrophyte density $(C)$ is shown in Fig. 2c. The $\mathrm{pH}$ was fixed at 7 , and salinity was fixed at $2.5 \mathrm{~g} / \mathrm{L}$. As shown in figure, the higher the retention time and macrophyte density, the higher the AN removal efficiency. Maximum macrophyte density was beneficial for enhancing AN removal efficiency by providing optimal microbial activity and plant assimilation for nutrients (Nahlik and Mitsch 2006). This agreed with the findings reported by Samimi and Moghadam (2018) that AN removal increased as both macrophyte density and retention time were increased. Another similar trend was also presented in the study, in which macrophyte density factor showed the insignificant effect on AN removal when there was a low level of retention time factor. As the macrophyte density was at its maximum value of $30 \mathrm{~g} / \mathrm{L}$, the AN concentration was reduced by more than $50 \%$ to achieve below $20 \mathrm{mg} / \mathrm{L}$ in less than 5 days of retention time. Without salinity effect ( salinity $=0 \mathrm{~g} / \mathrm{L}$ ), only 4 days of retention time was required to reduce the AN concentration by half.

\section{Interactive effect of retention time $(B)$ and salinity $(D)$}

The interactive effect of retention time $(B)$ and salinity $(D)$ is shown in Fig. 2d, at which $\mathrm{pH}$ was fixed at 7 and macrophyte density was fixed at $17.5 \mathrm{~g} / \mathrm{L}$. The response surface plot showed that longer retention time and lower salinity were preferable for achieving higher AN removal efficiency. However, the effect of retention time on AN removal efficiency was less significant as salinity was increased. The effect of salinity was shown to be more dominant as compared to retention time on the $\mathrm{AN}$ removal performance. Besides, E. crassipes in water medium containing salinity of 2.5 and $5 \mathrm{~g} \mathrm{NaCl} / \mathrm{L}$ exhibited toxic symptoms due to salinity stress after one day of phytoremediation process, which included twisted leaves and chlorotic leaf margin (Zeng et al. 2013). It was also observed that the twisted leaves became necrotic as retention time increased and the symptoms appeared on the older leaves first, followed by the younger foliage. For phytoremediation experiment which contained $2.5 \mathrm{~g} \mathrm{NaCl} / \mathrm{L}$, the toxic symptoms ceased after four days of retention time, which showed that the E. crassipes adapted successfully

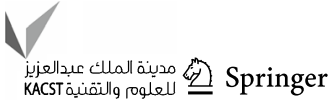


under these conditions. However, the toxic symptoms continued along the ten-day duration for phytoremediation set with salinity of $5 \mathrm{~g} \mathrm{NaCl} / \mathrm{L}$. Although the results showed that the E. crassipes was still capable of tolerating salinity of $2.5 \mathrm{~g} \mathrm{NaCl} / \mathrm{L}$, the attainment of negative biomass growth as well as observation of large amount of wilted and dead plants' parts at salinity of $5 \mathrm{~g} \mathrm{NaCl} / \mathrm{L}$ proved the unavailability of the $E$. crassipes for treating wastewater with extremely high salinity content.

\section{Interactive effect of $\mathrm{pH}(A)$ and macrophyte density $(C)$}

Figure 2e shows the interactive effect of $\mathrm{pH}(A)$ and macrophyte density $(C)$, at which retention time was fixed at 8 days and salinity was fixed at $2.5 \mathrm{~g} / \mathrm{L}$. Apparently, the AN removal efficiency increased as $\mathrm{pH}$ was increased, and at the same time, the effect of macrophyte density was found to be insignificant. This was because the growth of macrophyte was highly dependent on the $\mathrm{pH}$ of the medium. As macrophyte was provided with the medium of extreme $\mathrm{pH}$ condition, the growth of the plants would exhibit retarded or even deteriorated behavior (Shah et al. 2014). Since plants' growth was closely related to AN removal efficiency, extremely low or high $\mathrm{pH}$ environment was unfavorable for proper plants' growth and thus would adversely affect the AN removal efficiency (Ting et al. 2018).

\section{Interactive effect of $\mathrm{pH}(A)$ and salinity $(D)$}

Figure $2 \mathrm{f}$ shows the interactive effect of $\mathrm{pH}(A)$ and salinity $(D)$ on AN removal efficiency, at which retention time was fixed at 8 days and macrophyte density was fixed at $17.5 \mathrm{~g} / \mathrm{L}$. Under the acidic condition, the AN removal efficiency was found to be significantly influenced by the salinity variable. Phytoremediation system with wastewater medium containing both extreme salinity and $\mathrm{pH}$ conditions led to the highly stressful condition for plants' growth, and this finding was supported by the low biomass gain obtained after 8 days of phytoremediation process. De Casabianca et al. (1995) and Shah et al. (2014) reported on the zero biomass productivity of $E$. crassipes caused by stressful water medium, with $\mathrm{pH}$ higher than 10 and salinity higher than $6 \mathrm{~g} \mathrm{NaCl} / \mathrm{L}$, respectively. However, the response surface plot indicated that the effect of salinity became insignificant on the AN removal performance under alkaline condition. When salinity was increased from 1 to $5 \mathrm{~g} \mathrm{NaCl} / \mathrm{L}$, the $\mathrm{AN}$ removal efficiency decreased from approximately 40 to $20 \%$ at $\mathrm{pH} 4$, whereas at $\mathrm{pH} 10$, the $\mathrm{AN}$ removal efficiency decreased slightly from 87.5 to $85 \%$.

\section{Numerical optimization and results validation}

The optimum condition suggested by RSM was $\mathrm{pH} 8.51$, retention time of 8.47 days, macrophyte density of $21.39 \mathrm{~g} / \mathrm{L}$ and salinity of $0 \mathrm{~g} \mathrm{NaCl} / \mathrm{L}$. Under this condition, optimum responses were predicted as the following: AN removal efficiency of $77.48 \%$, fresh biomass growth of $218.95 \mathrm{~g}$, COD of $45.48 \mathrm{mg} / \mathrm{L}$, BOD of $2.64 \mathrm{mg} / \mathrm{L}$ and TSS of $5.80 \mathrm{mg} / \mathrm{L}$. In order to validate the predicted results, five replicates of the experiments were carried out which simulated the given optimum condition. The experimental results are shown in Table 4. The comparison between the experimental and predicted results was made based on relative standard error (RSE), defined as the standard error referring to the fraction of the estimate and usually displayed as a percentage. The estimates with an RSE $\geq 25 \%$ were considered as high sampling error and should be used with caution (Darajeh et al. 2016).

The validity of the model was further confirmed for two main responses, namely AN removal efficiency (\%) and fresh biomass growth $(\mathrm{g})$, with low mean RSE values of $5.79 \%$ and $10.11 \%$, respectively. Low RSE value indicated that the experimental values were determined to be close to the predicted values, which implied that the empirical models derived from the RSM experimental design could be adequately used to describe the relationship between the independent variables and the responses (Darajeh et al. 2016). The experimental results showed that high RSE values were exhibited by the responses of COD, BOD and TSS, with mean RSE values of $48.55 \%, 28.83 \%$ and $22.74 \%$, respectively. This indicated that the empirical models derived from RSM were inadequate to describe the relationship between

Table 4 Model validation results

\begin{tabular}{lllllllllrrr}
\hline Replicate & $\begin{array}{l}\text { AN removal } \\
\text { efficiency (\%) }\end{array}$ & RSE (\%) & $\begin{array}{l}\text { Fresh bio- } \\
\text { mass growth } \\
(\mathrm{g})\end{array}$ & RSE (\%) & COD (mg/L) & RSE (\%) & BOD (mg/L) & RSE (\%) & TSS (mg/L) & RSE (\%) \\
\hline 1 & 72.50 & 6.42 & 203.94 & 6.86 & 17 & 62.62 & 1.77 & 33.06 & 6 & 3.43 \\
2 & 80.00 & 3.26 & 257.89 & 17.78 & 35 & 23.04 & 1.55 & 41.38 & 8 & 37.91 \\
3 & 70.00 & 9.65 & 185.25 & 15.39 & 19 & 58.22 & 2.52 & 4.69 & 6 & 3.43 \\
4 & 75.00 & 3.20 & 227.39 & 3.85 & 24 & 47.23 & 2.01 & 23.98 & 9 & 55.15 \\
5 & 72.50 & 6.42 & 233.51 & 6.65 & 22 & 51.62 & 3.73 & 41.07 & 5 & 13.81 \\
\hline
\end{tabular}


Table 5 Model validation results using real semiconductor effluent

\begin{tabular}{|c|c|c|c|c|c|c|c|c|c|}
\hline \multirow[t]{2}{*}{ Replicate } & \multicolumn{2}{|c|}{$\begin{array}{l}\text { AN concentration } \\
(\mathrm{mg} / \mathrm{L})\end{array}$} & \multirow[t]{2}{*}{$\begin{array}{l}\text { AN removal } \\
\text { efficiency }(\%)\end{array}$} & \multicolumn{2}{|c|}{$\begin{array}{l}\text { Fresh biomass weight } \\
(\mathrm{g})\end{array}$} & \multirow[t]{2}{*}{$\begin{array}{l}\text { Fresh biomass } \\
\text { growth }(\mathrm{g})\end{array}$} & \multirow[t]{2}{*}{$\mathrm{COD}(\mathrm{mg} / \mathrm{L})$} & \multirow[t]{2}{*}{ BOD (mg/L) } & \multirow[t]{2}{*}{ TSS (mg/L) } \\
\hline & Initial & Final & & Initial & Final & & & & \\
\hline 1 & 24 & 10 & 58.33 & 204.34 & 284.72 & 80.38 & 37 & 1.7 & 2 \\
\hline 2 & 24 & 9 & 62.50 & 219.94 & 305.04 & 85.10 & 34 & 2.5 & 1 \\
\hline 3 & 24 & 10 & 58.33 & 209.29 & 302.44 & 93.15 & 31 & 2.1 & 2 \\
\hline
\end{tabular}

the input and these three output responses. The high RSE values of these responses were also due to the amplified standard error due to the involvement of relatively small values. As compared to the contribution of COD values, the BOD and TSS values were quite insignificant. However, the overall results regarding pollution load were still considered satisfactory since significantly lower COD values were obtained from all the five replicates of the experiments as compared to the predicted COD values.

Another set of validation experiment with three replicates was conducted using real semiconductor wastewater which simulated the optimum condition. The COD, BOD and TSS of the real semiconductor effluent prior to the phytoremediation process were found to be $92 \mathrm{mg} / \mathrm{L}, 36.4 \mathrm{mg} / \mathrm{L}$ and $1 \mathrm{mg} / \mathrm{L}$, respectively. Table 5 shows the model validation results for the treated semiconductor effluent. Under the simulated optimum condition, despite that lower AN removal efficiency was obtained for all three replicates as compared to the predicted AN removal efficiency, the goal to reduce the initial AN concentration by half had been achieved successfully. The achievement of lower AN removal efficiency was probably due to the lower biomass growth of $E$. crassipes in real semiconductor wastewater, as shown in Table 5. E. crassipes showed intolerant characteristic (i.e., yellowing of leaves) at the beginning of the experiment, possibly due to the stressful growth medium that contained high COD and BOD. However, the intolerant symptoms ceased after 3 days of retention time, and the plants exhibited healthy growth afterward. After the optimum retention time of 8.47 days, E. crassipes-based phytoremediation system was capable of reducing the COD and BOD contents significantly, with mean removal efficiency of $63.04 \%$ and $94.23 \%$, respectively. Additionally, there was only negligible increment of TSS values $(0-1 \mathrm{mg} / \mathrm{L})$ for the treated semiconductor effluent. Overall, the results showed that $E$. crassipes was capable of removing AN content in semiconductor effluent effectively without contributing extra pollutant load (i.e., COD, BOD, TSS) to the treated wastewater. This further confirmed that the models developed in this study were reliable and accurate to relate the variables to the responses, and the optimum condition obtained was feasible to be applied to remove AN from real semiconductor wastewater.

\section{Conclusions}

Face-centered central composite design was employed to optimize the AN removal efficiency through E. crassipesbased phytoremediation system. The two-factor interaction (2FI) model was successfully developed for the response of AN removal efficiency. The model adequacy was evaluated through ANOVA, at which the model significance was confirmed by attainment of high $R^{2}$ value of 0.9208 and model $F$ value of 19.77. Through numerical optimization, the highest AN removal efficiency of $77.48 \%$ was obtained at the following optimum condition: $\mathrm{pH} 8.51$, retention time of 8.47 days, macrophyte density of $21.39 \mathrm{~g} / \mathrm{L}$ and salinity of $0 \mathrm{~g} \mathrm{NaCl} / \mathrm{L}$. Based on the experimental results, low mean RSE values of $5.79 \%$ were obtained for the response of AN removal efficiency, which confirmed the validity of the empirical model developed and implied that the RSM method was practical to be employed for the process optimization. The validation experiment using real semiconductor effluent further provided evidence on the efficiency of $E$. crassipes to remove $\mathrm{AN}, \mathrm{COD}$ and BOD in the effluent. Overall, phytoremediation using E. crassipes has been shown to be promising for AN removal in wastewater.

Acknowledgements The authors acknowledge the research grants provided by Universiti Malaysia Sarawak under Fundamental Research Grant Scheme FRGS/TK02(05)/1305/2015(22) from Ministry of Higher Education Malaysia.

\section{Compliance with ethical standards}

Conflict of interest The authors declare that they have no conflicts of interest regarding the publication of this paper.

Open Access This article is licensed under a Creative Commons Attribution 4.0 International License, which permits use, sharing, adaptation, distribution and reproduction in any medium or format, as long as you give appropriate credit to the original author(s) and the source, provide a link to the Creative Commons licence, and indicate if changes were made. The images or other third party material in this article are included in the article's Creative Commons licence, unless indicated otherwise in a credit line to the material. If material is not included in the article's Creative Commons licence and your intended use is not permitted by statutory regulation or exceeds the permitted use, you will need to obtain permission directly from the copyright holder. To view a copy of this licence, visit http://creativecommons.org/licenses/by/4.0/.

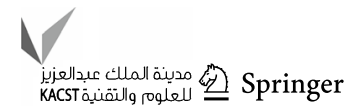




\section{References}

Al-Baldawi IAW, Abdullah SRS, Abu Hasan H, Suja F, Anuar N, Mushrifah I (2014) Optimized conditions for phytoremediation of diesel by Scirpus grossus in horizontal subsurface flow constructed wetlands (HSFCWs) using response surface methodology. J Environ Manag 140:152-159

Aoudj S, Khelifa A, Drouiche N (2017) Removal of fluoride, SDS, ammonia and turbidity from semiconductor wastewater by combined electrocoagulation-electroflotation. Chemosphere 180:379-387

APHA (2005) Standard methods for the examination of water and wastewater, 21st edn. American Public Health Association, Washington DC

Bashir MJK, Abu Amr SS, Shuokr QA, Ng CA, Sumathi S (2015) Wastewater treatment processes optimization using response surface methodology (RSM) compared with conventional methods: review and comparative study. Middle East J Sci Res 23(2):244-252

Caicedo JR, Vn der Steen NP, Arce O, Gijzen HJ (2000) Effect of total ammonia nitrogen concentration and $\mathrm{pH}$ on growth rates of duckweed (Spirodela polyrrhiza). Water Res 34:3829-3835

Caraiman P, Pohontu C, Soreanu G, Macoveanu M, Cretescu I (2012) Optimization process of cadmium and zinc removal from soil by phytoremediation using Brassica napus and Triticales sp. Environ Eng Manag J 11(2):271-278

Darajeh N, Idris A, Masoumi HRF, Nourani A, Truong P, Sairi NA (2016) Modeling BOD and COD removal from palm oil mill secondary effluent in floating wetland by Chrysopogon zizanioides (L.) using response surface methodology. J Environ Manag 181:343-352

De Casabianca ML, Laughier T, Posada F (1995) Petroliferous wastewaters treatment with water hyacinth (Raffinerie de Provence, France): experimental statement. Waste Manag 15:651-655

Dixit A, Dixit S, Goswami CS (2011) Process and plants for wastewater remediation: a review. Sci Rev Chem Commun 1:71-77

Edaigbini PI, Ogbeide SE, Olafuyi OA (2015) A comparative study of the performance of water hyacinth (Eichhornia crassipes) and water lettuce (Pistia stratiotes) in the remediation of produced water. J Energy Technol Policy 5:1-9

El-Gendy AS, Biswas N, Bewtra JK (2004) Growth of water hyacinth in municipal landfill leachate with different $\mathrm{pH}$. Environ Technol 25(7):833-840

Fox LJ, Struik PC, Appleton BL, Rule JH (2008) Nitrogen phytoremediation by water hyacinth [Eichhornia crassipes (Mart.) solms]. Water Air Soil Pollut 194:199-207

Gupta P, Roy S, Mahindrakar AB (2012) Treatment of water using water hyacinth, water lettuce and vetiver grass-a review. Resour Environ 2:202-215

Huang H, Liu J, Zhang P, Zhang D, Gao F (2017) Investigation on the simultaneous removal of fluoride, ammonia nitrogen and phosphate from semiconductor wastewater using chemical precipitation. Chem Eng J 307:696-706

Kumar V, Singh J, Kumar P (2018) Response surface methodology based optimization of cadmium and lead remediation from aqueous solution by water hyacinth [Eichhornia crassipes (Mart.) Solms] and its anatomical study. Arch Agric Environ Sci 3(2): 163-173

Kumari M, Tripathi BD (2013) Effect of aeration and mixed culture of Eichhornia crassipes and Salvinia natans on removal of wastewater pollutants. Ecol Eng 62:48-53

Loan NT, Phuong NM, Anh NTN (2014) The role of aquatic plants and microorganisms in domestic wastewater treatment. Environ Eng Manag J 13(8):2031-2038
Lu M, Wei X, Xiao M, Zhang Z, Su Y (2013) Multi-process bioremediation as an improved approach for petroleum-contaminated soil restoration. Pet Sci Technol 31(1):94-100

Lu Q, Zhenli LH, Donald AG, Peter JS, Xiaoe Y (2008) Phytoremediation to remove nutrients and improve eutrophic stormwaters using water lettuce (Pistia stratiotes L.). Environ Sci Pollut Res 17:84-96

Mishra S, Maiti A (2017) The efficiency of Eichhornia crassipes in the removal of organic and inorganic pollutants from wastewater: a review. Environ Sci Pollut Res 24:7921-7937

Nahlik AM, Mitsch WJ (2006) Tropical treatment wetlands dominated by free-floating macrophytes for water quality improvement in Costa Rica. Ecol Eng 28:246-257

Nayanathara OS, Bindu AG (2017) Effectiveness of water hyacinth and water lettuce for the treatment of greywater-a review. Int J Innov Res Sci Eng 3:349-355

Neffati M, Marzouk B (2010) Salinity impact on growth, essential oil content and composition of Coriander (Coriandrum sativum L.) stems and leaves. J Essent Oil Res 22(1):29-34

Nur Farehah ZA, Norli I, Siti Norfariha MN, Siti Aisyah I, Renuka R (2014) Ammoniacal nitrogen removal in semiconductor wastewater by sequence batch reactor using bacteria inoculum from worm tea. J Med Bioeng 3(4):241-244

Paz-Alberto AM, Sigua GC (2013) Phytoremediation a green technology to remove environmental pollutants. AJCC 2:71-86

Pedron F, Petruzzelli G (2011) Green remediation strategies to improve the quality of contaminated soils. Chem Ecol 27(S1):89-95

Qin H, Zhang Z, Liu M, Wang Y, Wen X, Zhang Y, Yan S (2016) Site test of phytoremediation of an open pond contaminated with domestic sewage using water hyacinth and water lettuce. Ecol Eng 95:753-762

Rai PK, Singh MM (2016) Eichhornia crasssipes as a potential phytoremediation agent and an important bioresource for Asia Pacific region. Environ Skept Crit 5:12-19

Rezania S, Ponraj M, Talaiekhozani A, Mohamad SE, Md Din MF, Taib SM, Sabbagh F, Md Sairan F (2015) Perspectives of phytoremediation using water hyacinth for removal of heavy metals, organic and inorganic pollutants in wastewater. J Environ Manag 163:125-133

Samimi M, Moghadam SM (2018) Optimal conditions for the biological removal of ammonia from wastewater of a petrochemical plant using the response surface methodology. Global J Environ Sci Manag 4(3):315-324

Seroja R, Effendi H, Hariyadi S (2018) Tofu wastewater treatment using vetiver grass (Vetiveria zizanioides) and zeliac. Appl Water Sci 8(2):1-6

Shah M, Hashmi HN, Ali A, Ghumman AR (2014) Performance assessment of aquatic macrophytes for treatment of municipal wastewater. J Environ Health Sci Eng 12:106-118

Ting WHT, Tan IAW, Salleh SF, Wahab NA (2018) Application of water hyacinth (Eichhornia crassipes) for phytoremediation of ammoniacal nitrogen: a review. J Water Process Eng 22:239-249

Titah HS, Halmi MIE, Abdullah SRS, Hasan HA, Idris M, Anuar N (2018) Statistical optimization of the phytoremediation of arsenic by Ludwigia octovalvis- in a pilot reed bed using response surface methodology (RSM) versus an artificial neural network (ANN). Int J Phytoremediation 20(7):721-729

Valipour A, Raman VK, Ahn Y (2015) Effectiveness of domestic wastewater treatment using a bio-hedge water hyacinth wetland system. Water 7:329-347

Wong YC, Moganaragi V, Atiqah NA (2013) Physico-chemical investigations of semiconductor industrial wastewater orient. J Chem 29(4):1421-1428

Xiang S, Haijing S, Hongwei P, Yitai C, Zeping J, Jianfeng L, Shufeng W (2015) Growth and efficiency of nutrient removal by Salix 
jiangsuensis $\mathrm{J} 172$ for phytoremediation of urban wastewater. Environ Sci Pollut Res 23:2715-2723

Yahyapour S, Golshan A, Ghazali AH (2014) Removal of total suspended solids and turbidity within experimental vegetated channel: optimization through response surface methodology. J HydroEnviron Res 8(3):260-269

Zeng F, Shabala L, Zhou M, Zhang G, Shabal S (2013) Barley responses to combined waterlogging and salinity stress: separating effects of oxygen deprivation and elemental toxicity. Front Plant Sci 4:313

Zhang BY, Zheng JS, Sharp RG (2010) Phytoremediation in engineered wetlands: mechanisms and applications. Procedia Environ Sci 2:1315-1325
Zhao H, Wang F, Ji M, Yang J (2014) Effects of salinity on removal of nitrogen and phosphorus from eutrophic saline water in planted Lythrum salicaria L. microcosm systems. Desalin Water Treat 52:34-36

Publisher's Note Springer Nature remains neutral with regard to jurisdictional claims in published maps and institutional affiliations. 